\title{
Conquering the Odds: Cirsoid Aneurysm with Holocranial Feeders - Staged Embolization, Excision, and Grafting
}

\author{
Sunil Munakomi ${ }^{1}$, Iype Cherian ${ }^{2}$, Binod Bhattarai ${ }^{2}$, Karuna Tamrakar ${ }^{2}$ \\ 1. Neurosurgery, Nobel Teaching Hospital, Nepal 2. Neurosurgery, College of Medical Sciences, \\ Bharatpur, Nepal
}

$\square$ Corresponding author: Sunil Munakomi, sunilmunakomi@gmail.com Disclosures can be found in Additional Information at the end of the article

\section{Abstract}

Arteriovenous malformation (AVM) of the scalp is an uncommon entity. Its management is difficult because of its high shunt flow, complex vascular anatomy, and possible cosmetic complications. The etiology of scalp AVMs, i.e., cirsoid aneurysm, may be spontaneous or traumatic. Clinical symptoms frequently include pulsatile mass, headache, local pain, tinnitus, and less frequently, hemorrhage and necrosis. Selective angiography is the most common diagnosis method. Surgical excision is especially effective in AVMs and the most frequently used treatment method. Here, we present one such case where staged embolization, excision, and subsequent grafting was done.

Categories: Neurosurgery

Keywords: arteriovenous malformation, scalp cirsoid aneurysm, treatment

\section{Introduction}

An arteriovenous malformation (AVM) of the scalp is an abnormal fistulous connection between the feeding arteries and draining veins, without an intervening capillary bed within the subcutaneous layer [1-2]. AVM of the scalp is a rare lesion [2-3]. Its management is difficult because of its high shunt flow, complex vascular anatomy, and possible cosmetic complications [3-4]. The origin of AVM of the scalp is still uncertain, but trauma is an important factor in most of the patients [3-4]. Clinical symptoms frequently include pulsatile mass, headache, local pain, tinnitus, and less frequently, hemorrhage and necrosis [3, 5-6]. Surgical treatment is particularly indicated in order to rule out bleeding, for the resolution of cosmetic problems, and in the case of tinnitus and headache [4, 6-7].

Received 09/22/2014 Review began 09/27/2014 Review ended 09/29/2014 Published 09/30/2014

\section{Copyright 2014}

Munakomi et al. This is an open access article distributed under the terms of the Creative Commons Attribution License CC-BY 3.0., which permits unrestricted use, distribution, and reproduction in any medium, provided the original author and source are credited.
Here, we present one such case where staged embolization, excision, and subsequent grafting was done. Informed patient consent was obtained for all procedures.

\section{Case Presentation}

A 38-year-old female presented with the complaint of slowly progressive swelling over scalp for the past 20 years. There was no history of trauma, loss of consciousness, headache, vomiting, altered sensorium, or weakness of body parts. Surgical excision was attempted in an outside centre without a prior angiogram, which needed to be stopped due to heavy bleeding.

On examination, there was a swelling of size $12 \times 4 \mathrm{~cm}^{2}$ in the forehead and the scalp, which was 


\section{Cureus}

slightly compressible with audible bruit over the swelling figure (Figure 1) and (Figure 2).

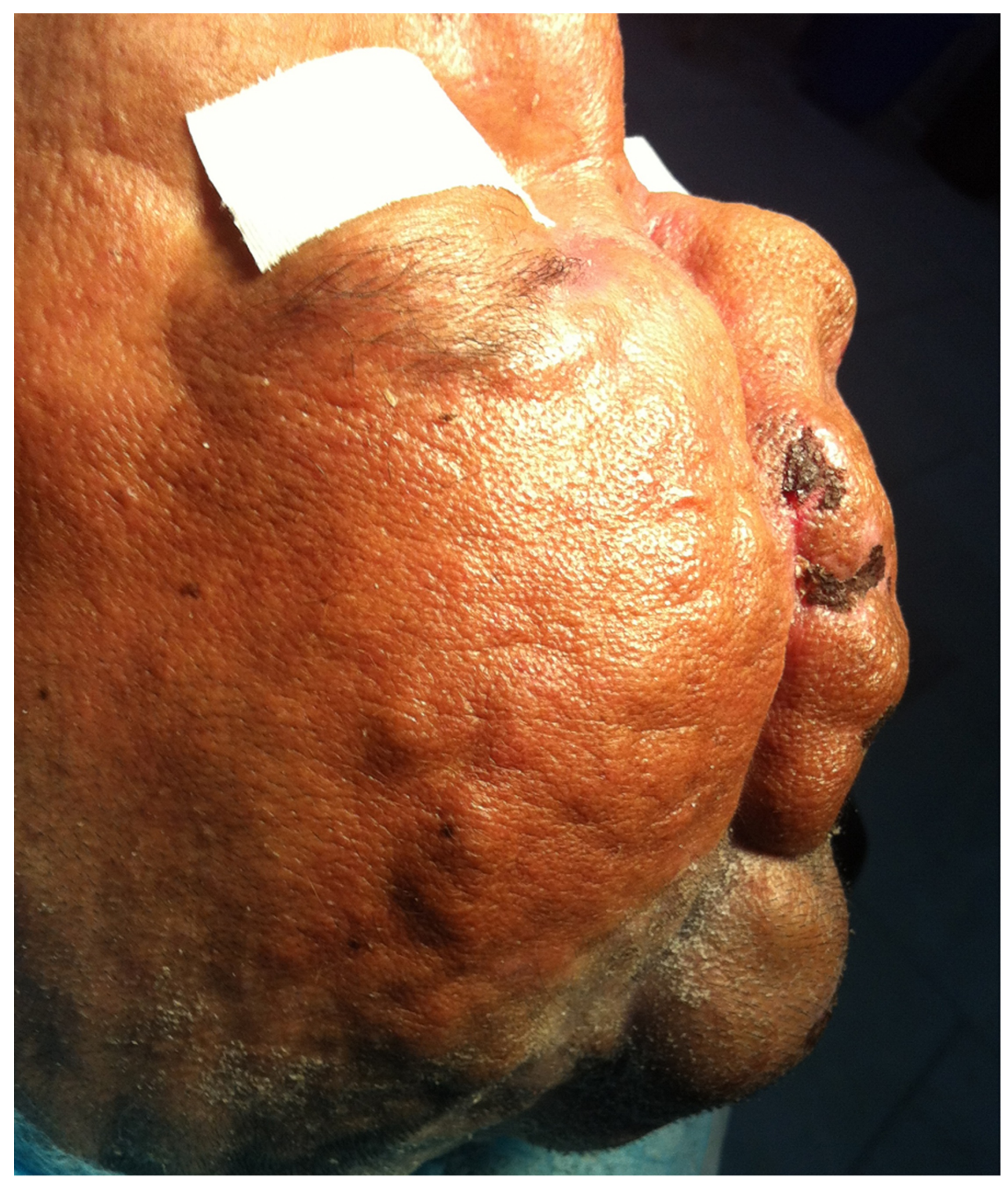

FIGURE 1: Lateral View with Patient Lying Supine in the Table 


\section{Cureus}

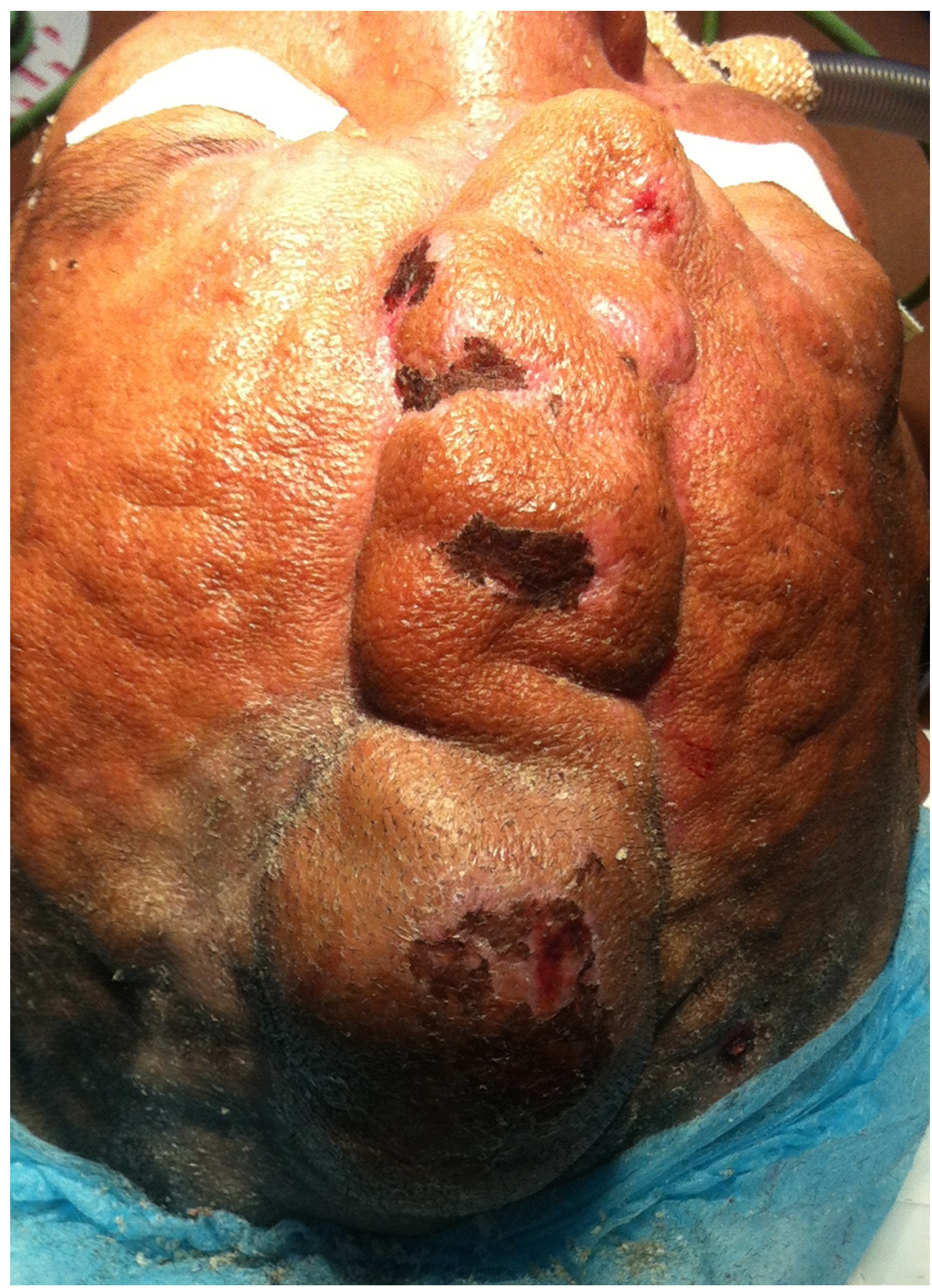

FIGURE 2: Intraoperative Picture

MRI (Figure 3) and CT revealed multiple dilated and tortuous vessels over the scalp in the frontal and both temporal and parietal regions with multiple collaterals. Right transverse, sigmoid, and jugular bulb were asymmetrically prominent. Angiography revealed a cirsoid aneurysm with feeders from external carotid (superficial temporal, retroauricular, and occipital), internal carotid (parasiting vessels from the callosomarginal arteries), and the left P2 via left vertebral arteries. 


\section{Cureus}

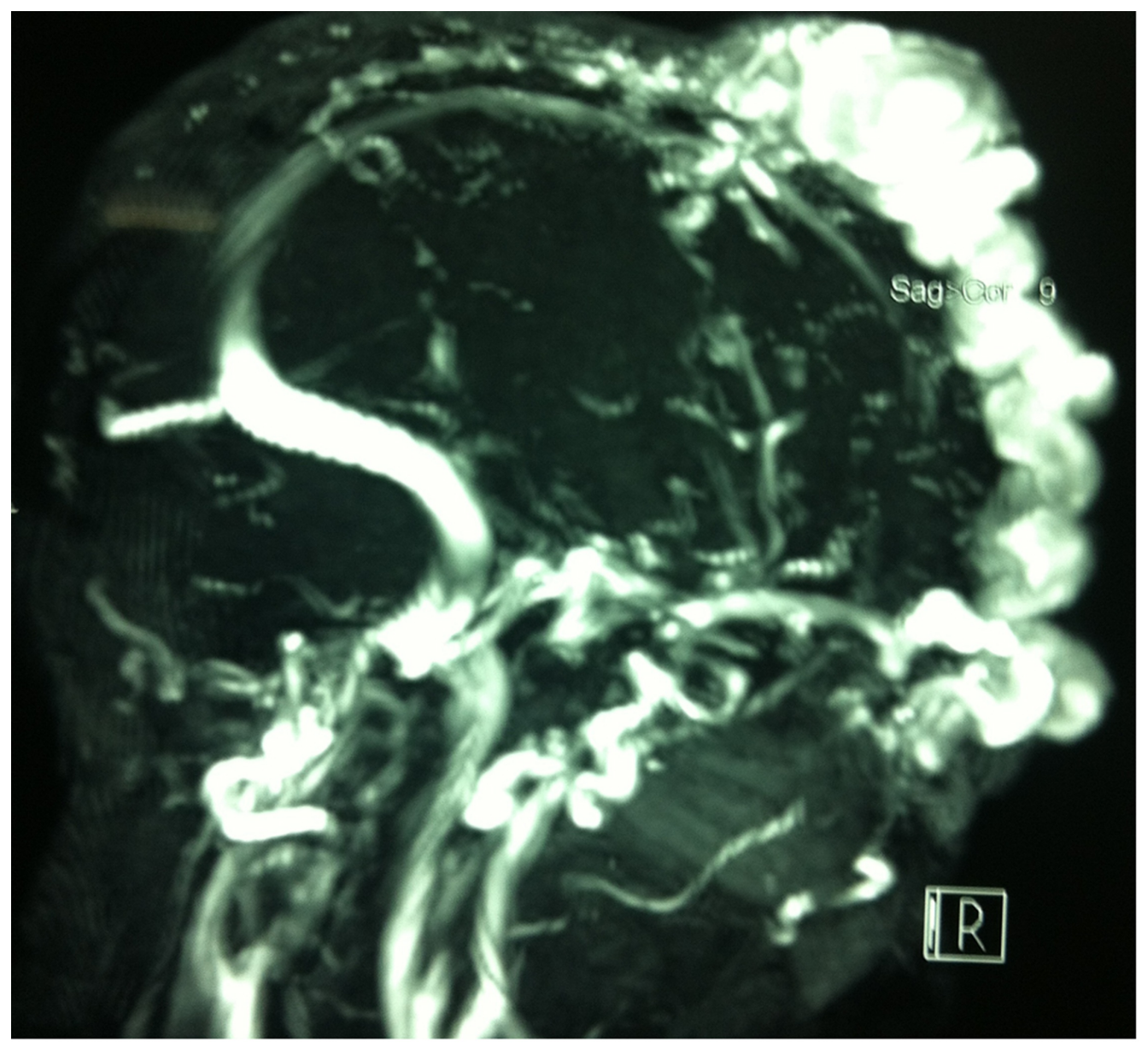

\section{FIGURE 3: MR Venography}

The patient underwent angiographic embolization of the feeders from the external carotid arteries (Figure 4) and (Figure 5) as a staged procedure. Care was taken to digitally compress the varix edges to prevent an inadvertent embolic particle to enter the intracranial venous system. Ligation of the remaining feeders and excision of the varix with primary suturing of the scalp defect (Figure 6) was done 10 days later. The patient was started with LMW Heparin and Dextran to prevent propagating thrombus in the deep sinuses. 


\section{Cureus}

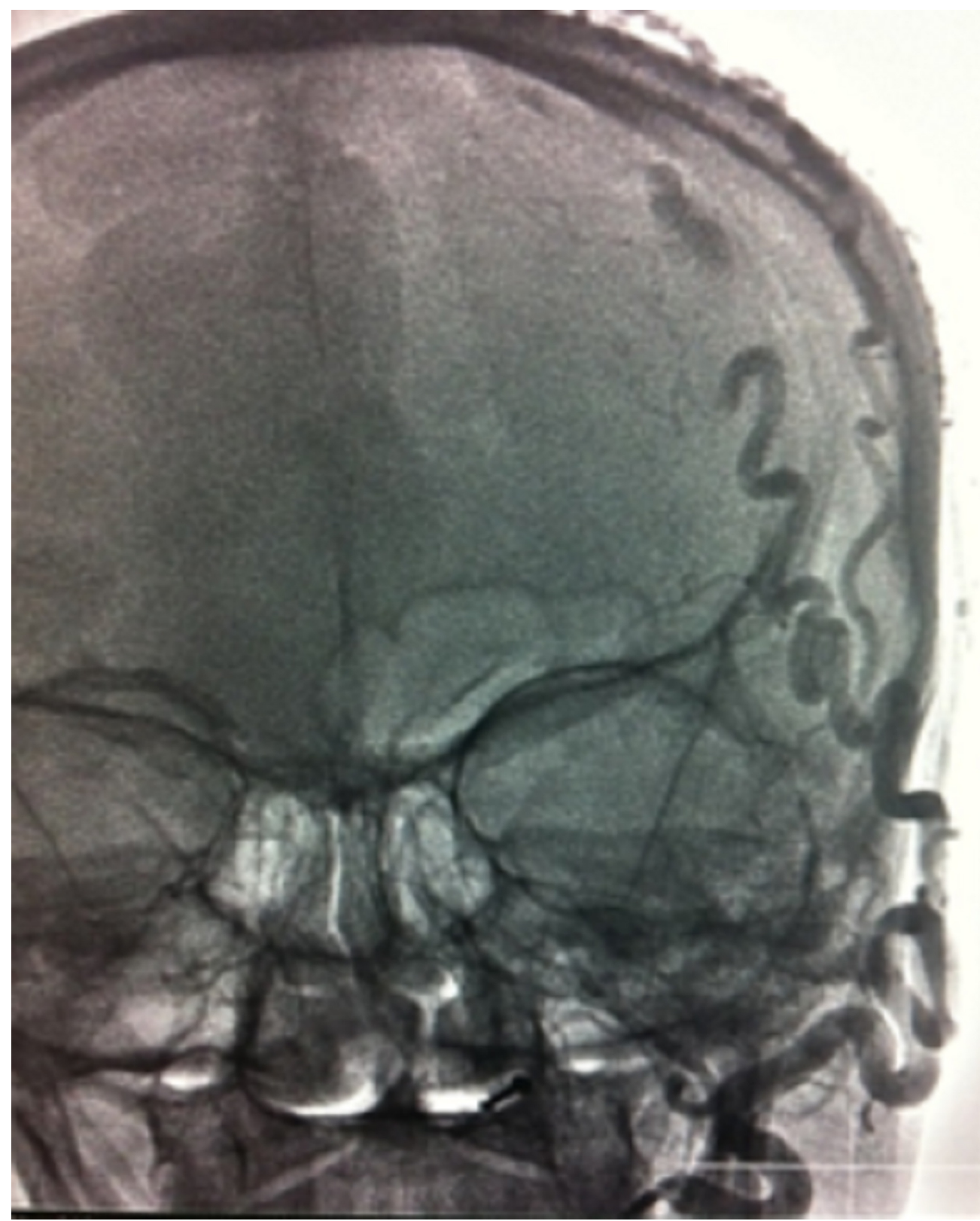

FIGURE 4: Feeder From External Carotid Artery 


\section{Cureus}

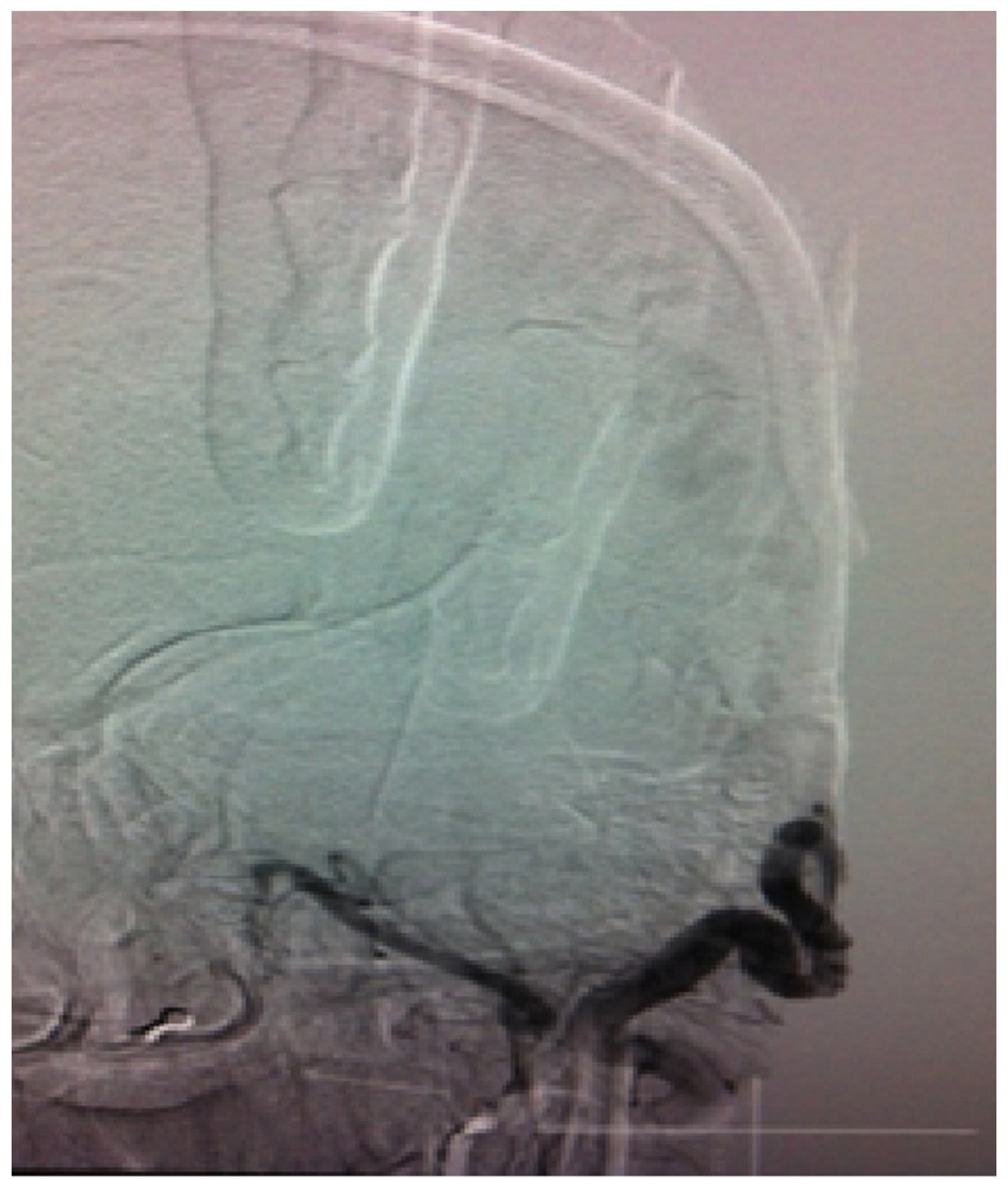

FIGURE 5: Complete Obliteration of Feeder After Embolisation 


\section{Cureus}

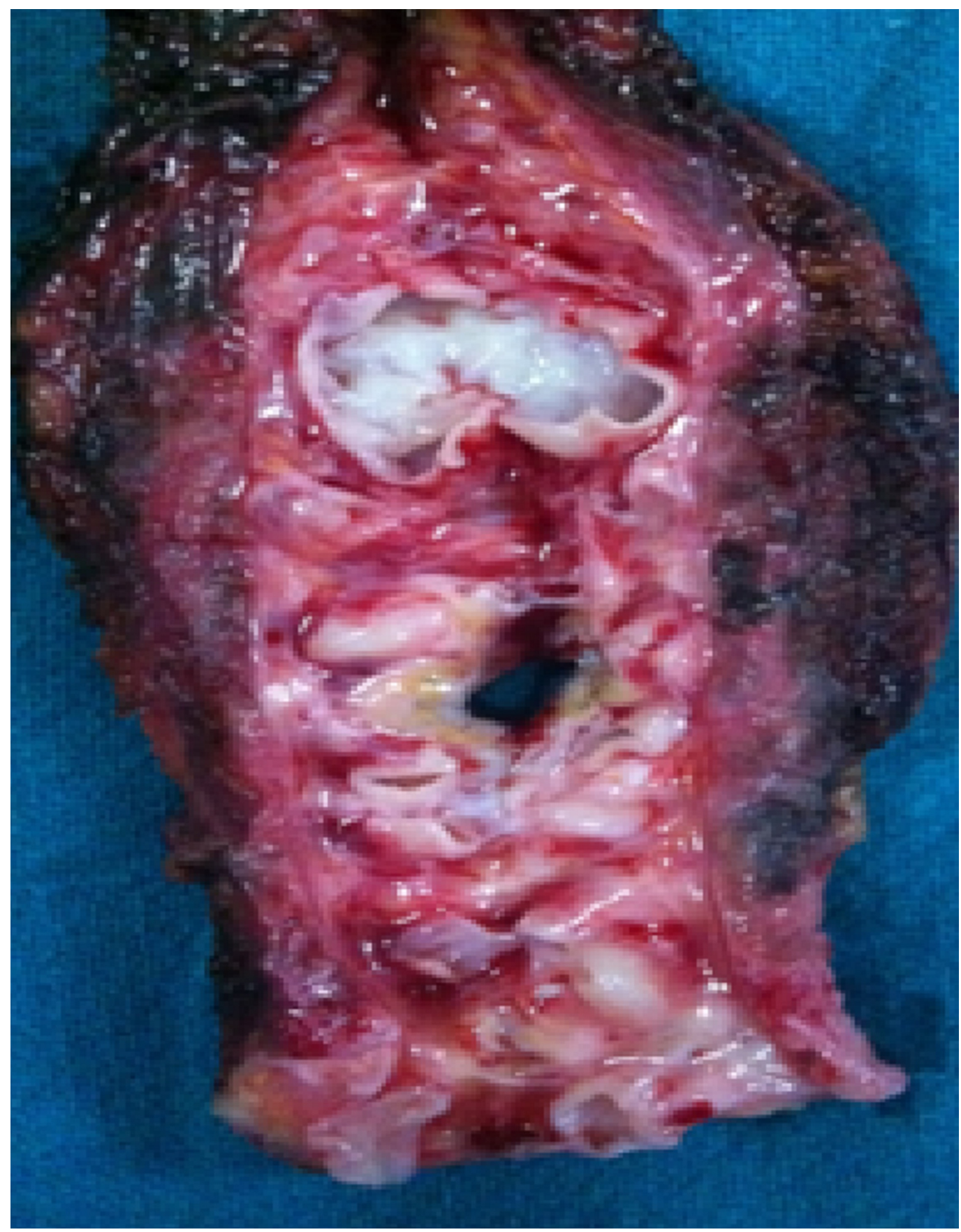

FIGURE 6: Excised Varix

Post-embolization and excision, a CT scan showed no evidence of intracranial propagation of thrombus. The patient subsequently underwent skin grafting over the defect in the scalp due to the ischemic edges of the defect (Figure 7). The patient made an uneventful recovery. Postoperative angiography showed only feeders from left occipital branch supplying the scalp. 


\section{Cureus}

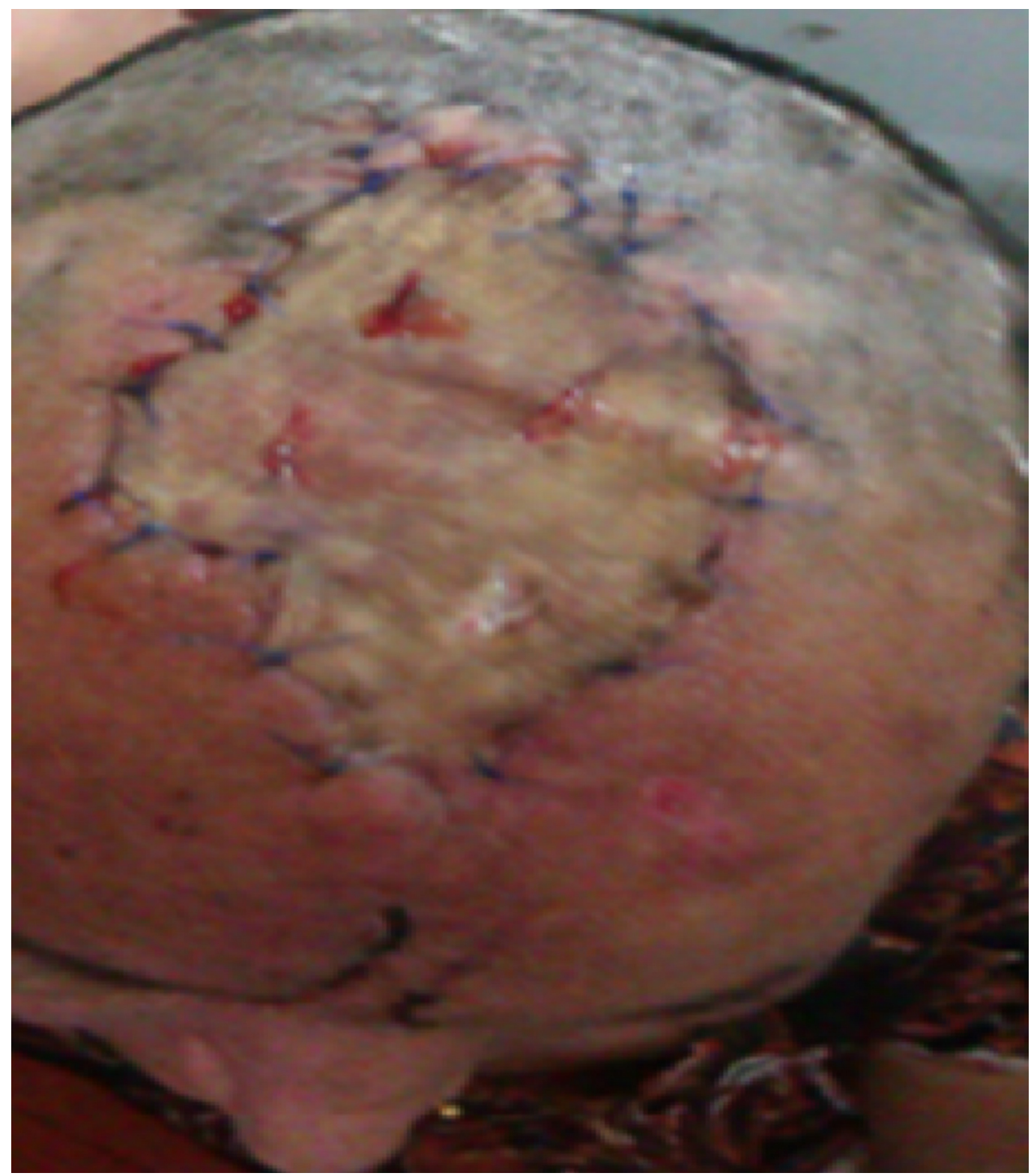

FIGURE 7: Wound After Skin Grafting

\section{Discussion}

AVM of the scalp is an uncommon entity [1-2]. Various names are used to describe the vascular malformations of the scalp, including aneurysm cirsoides, aneurysma serpentinum, plexiform angioma, arteriovenous fistula, and AVM [3-5]. The most frequent sites of involvement are frontal, temporal, and parietal regions [3, 5-6]. The origin of the main feeder is in the subcutaneous tissue of the scalp. The origin of these main feeders most frequently arises from the external carotid, occipital, and supraorbital arteries. The superficial temporal artery (STA) is frequently involved in traumatic cirsoid aneurysm [5-7]. The etiology of these lesions remains controversial. The etiology of scalp AVMs may be spontaneous or traumatic [4, 8]. They generally develop in the trauma background and in patients over 30 years old. Spontaneous AVM of the scalp may present at birth; however, in most patients, it is asymptomatic until adulthood [3, 8-9]. Trauma, pregnancy, or hormonal changes cause deterioration of the symptoms. Traumatic AVM of the scalp develops months or years after the scalp trauma. 
About 10 to $20 \%$ of scalp AVMs develop following penetrating or non-penetrating trauma to the scalp $[7-8,10]$. Their clinical signs are associated with the size of the AVM. The patients may present with headache, numbness, and/or hemorrhage. Others may present with local symptoms, such as scalp lesions. Hemorrhage is generally uncommon but may develop in the event of large vascular malformations. Recurrent hemorrhage, which rapidly deteriorates the neurological status, may be seen in some of the patients $[1,3,8]$. The quality of the neuroradiological diagnosis is important for the surgical procedure to be performed, and cranial angiography is of great significance for diagnosis and treatment selection. Selective angiography should be carried out with the differential diagnosis of other vascular lesions, such as aneurysms, sinus pericranii, venous malformation, and cavernous hemangioma $[2,8$, 10]. Brain MRA is also of significance for establishing a diagnosis. Scalp AVMs are most frequently confused with hemangiomas and cavernomas. No arteriovenous shunt is present in such pathologies, and they are seen as well-demarcated lesions. AVMs show flow void signs on MRI due to the rapid flow in the lesion $[1,8,10]$. Surgical excision is especially effective in AVMs, and is the most frequently used treatment method $[4,7,11]$. AVMs are generally located in the periosteal and temporal fascia or under the galea. Thus, the preoperative radiological evaluation should be used for the assessment of feeding arteries, drainage vessels, numbers of fistulas, connected vascular structures, and shunt flow volume in order to prevent any possible complications $[3,5,7]$.

One of the substantial complications during the operation is hemorrhage. Hemorrhage may be prevented with preoperative embolization, clamping, and suturing of feeding vessels. The scalp flap is removed with the pericranium, which particularly prevents rupture $[5,7,11]$. The AVM may not always be related to the cranium. Infection and sepsis as well as hemorrhage and necrosis may be seen as complications $[1,5,10]$. In order to decrease the hemorrhage, endovascular treatment may be applied in the direct treatment of AVMs or to facilitate surgical treatment $[4,7,11]$. Embolization of preoperative nidus and feeders especially prevents massive hemorrhage. Embolization and endovascular treatment may not be sufficient in the treatment of large scalp AVMs. Incomplete surgical resection is also insufficient for the treatment. This may cause scalp hemorrhage and necrosis in elderly patients [7-8, 10]. Despite these treatments, recurrence due to feeding collaterals may develop. The most important step is total surgical excision without causing scalp necrosis and excessive blood loss. Furthermore, a better cosmetic result may be obtained $[1,3,10]$. However, when not possible, a feasible option could be achieved by free graft of the scalp defect over healthy granulation tissue.

\section{Conclusions}

The objective of scalp AVM treatment is to eliminate the clinical complaints affecting the patient's cosmesis. Treatment options include surgery, endovascular/percutaneous embolization, electrothrombosis, and combined approaches. Definitive treatment may be provided with embolization in those patients with appropriate angiographic characteristics. In the event of scalp necrosis and excessive blood loss, total excision is the fundamental treatment selection. In this case, a staged embolization, excision, and grafting is thought to be the best feasible option.

\section{Additional Information}

\section{Disclosures}

Human subjects: Consent was obtained by all participants in this study. College of Medical Sciences Ethical Review Commiittee issued approval. Conflicts of interest: In compliance with the ICMJE uniform disclosure form, all authors declare the following: Payment/services info: All authors have declared that no financial support was received from any organization for the submitted work. Financial relationships: All authors have declared that they have no financial relationships at present or within the previous three years with any organizations that 
might have an interest in the submitted work. Other relationships: All authors have declared that there are no other relationships or activities that could appear to have influenced the submitted work.

\section{References}

1. Senoglu M, Yasim A, Gokce M, Senoglu N: Nontraumatic scalp arteriovenous fistula in an adult: Technical report on an illustrative case. Surg Neurol. 2008, 70:194-7. 10.1016/j.surneu.2007.04.018

2. Muthukumar N, Rajagopal V, Manoharan AV, Durairaj N: Surgical management of cirsoid aneurysms. Acta Neurochir (Wien). 2002, 144:349-56.

3. Shenoy SN, Raja A: Scalp arteriovenous malformations. Neurol India. 2004, 52:478-81.

4. Massimi L, De Bonis P, Esposito G, Novegno F, Pettorini B, Tamburrini G, Caldarelli M, Di Rocco C: Vertex scalp mass as presenting sign of a complex intracranial vascular malformation. J Neurosurg Pediatr. 2009, 3:307-10. 10.3171/2008.12.PEDS08408

5. Heilman CB, Kwan ES, Klucznik RP, Cohen AR: Elimination of a cirsoid aneurysm of the scalp by direct percutaneous embolization with thrombogenic coils. Case report. J Neurosurg. 1990, 73:296-300.

6. Burrus TM, Miller GM, Flynn LP, Fulgham JR, Lanzino G: NeuroImages. Symptomatic left temporal arteriovenous traumatic fistula. Neurology. 2009, 73:570.

10.1212/WNL.0b013e3181b2a6f1

7. Gupta AK, Purkayastha S, Bodhey NK, Kapilamoorthy TR, Krishnamoorthy T, Kesavadas C, Thomas B: Endovascular treatment of scalp cirsoid aneurysms. Neurol India. 2008, 56:167-72.

8. Fisher-Jeffes ND, Domingo Z, Madden M, de Villiers JC: Arteriovenous malformations of the scalp. Neurosurg. 1995, 36:656-60.

9. Li F, Zhu S, Liu Y, Chen Y, Chi L, Chen G, Zhang J, Qu F: Traumatic arteriovenous fistula of the superficial temporal artery. J Clin Neurosci. 2007, 14:595-600.

10. Matsushige T, Kiya K, Satoh H, Mizoue T, Kagawa K, Araki H: Arteriovenous malformation of the scalp: Case report and review of the literature. Surg Neurol. 2004, 62:253-9.

11. Tiwary SK, Khanna R, Khanna AK: Craniofacial cirsoid aneurysm: 2-stage treatment . J Oral Maxillofac Surg. 2007, 65:523-5. 